\title{
A PV Module Integrated Converter for Enhanced Perfomance in Standalone and DC Microgrid Applications
}

\author{
M.Padma Lalitha, Pasala Gopi, K.Omkar
}

\begin{abstract}
The aim of these design toward plot and execute greatest power point following (MPPT) that makes utilize of a fluffy rationale control algorithm. Fluffy rationale, via using dealing with nonlinearities, gives a regular controller used for this form of utilization. The technique likewise income by the heuristic way to deal with the problem that beats the intricacy in demonstrating nonlinear frameworks. Therefore as to perform this objective, MPPT model comprising of a PV module, a DC$D C$ converter, and a fluffy rationale controller become created. Examination of buck, converter as well as buck-support converter attributes changed into done within an effort on the way to distinguish the most appropriate topology. An incorporated copy of the PV module along with the distinguished converter became reproduced also the effects worn to determine the grasp studying predicted near devise also music the fluffy rationale regulator. The regulator changed into veiled the same as an ongoing control application and the MPPT finished via a $d c$-dc converter constrained by means of a microcontroller. These results in progressed productiveness in favor of the hobby of a photovoltaic strength framework considering battery may be accurately charged and applied in the course of times of low sunlight based radiation. The better productiveness is relied upon to set off essential value funding funds over the long haul. The well known price is saved low through choosing segments that take into account executing the capacities requiring little to no effort. Reenactment outcomes demonstrate the high estimation of the element coordinated converter for DC unbiased and microgrid packages. A $400 \mathrm{~W}$ model changed into completed by 0.14 Euro/W. Testing established efficiencies over 95\% thinking about every misfortunes from have an effect on trade, fuzzy logic MPPT, and estimation and manage hardware.
\end{abstract}

Rundown phrases - Boost converter, fuzzy logic most extreme power point following (DMPPT), microgrid, and module coordinated converter (MIC), photovoltaics $(P V)$, control analyzer, control quality, sun based irradiance, exchanging recurrence tweak (SFM).

\section{INTRODUCTION}

Because of overdue, the utilization of photovoltaic (PV) energy has encountered noteworthy advancement as a desire to tackle power problems in spots through high solar based thickness, that's due to infection, introduced approximately by way of non-renewable energy sources and the steady decline of charges of the PV modules. Shockingly, the

Revised Manuscript Received on July 18, 2019.

Dr.M.Padma Lalitha, Dep.of Electrical Engineering, AITS Rajampeta, Kadapa, Andhra Pradesh-516126, India. (E-mail: padmalalitha.mareddy@gmail.com)

Dr.Pasala Gopi, Dep.of Electrical Engineering, AITS Rajampeta, Kadapa, Andhra Pradesh-516126, India. (E-mail: pasala.epe07@gmail.com)

K.Omkar, Dep.of Electrical Engineering, AITS Rajampeta, Kadapa, Andhra Pradesh-516126,

India vitality change productivity of the PV modules be low, which diminishes the money saving advantage percentage of PV frameworks.

The upper limit intense strength that a PV module can provide is controlled with the aid of the end result of the present day as well as the voltage on the greatest strength factor, which is based upon the operating temperature also the sun based irradiance. The short out present day of a PV module is legitimately relative to the sun oriented irradiance, diminishing significantly because the illumination diminishes, at the same time as the open circuit voltage shifts modestly because of adjustments in light. Conversely, the voltage diminishes appreciably when the temperature increments, whilst the quick out modern increments fairly.

In rundown, expanded solar powered mild promises increased short out modern-day, whilst elevated temperature decline the open circuit voltage, which affect the yield intensity of the PV module. This fluctuation of the yield electricity implies that without a coupling gadget among the PV module as well as the heap, the framework does no longer work at the most severe power factor (MPP).

This document introduces the shape as well as showing of a fluffy controller to observe the finest strength purpose of a PV module, using the qualities of fluffy motive to speak to an trouble via etymological articulations [1]. This paper well-known shows as a interest the usage of the clinical representation anticipated in [2], [3] for showing the PV module, which, numerous to diode primarily base fashions, just desires to examine the bend right constraint. The effects had been contrasted and the P\&O controller, which exhibited to facilitate the future technique indicates fewer power misfortunes what's more, guarantees MPP in all cases assessed in reenactment. It deserves referencing that this paintings is a chunk of a number of sensible manage procedures being assessed inside the examination bunch Magma Ingeniería of the Universidad Del Magdalena with the goal that you can execute a MPPT controller of case and high effectiveness.

The primary target of this design is the shape, showing and reproduction of a fluffy rationale controller and a dc-dc converter for an off-network PV framework. In a subsequent stage, the fluffy rationale controller can be actualized utilizing the minimum attempt Arduino stage [3], taking as a type of attitude the facts elements, yield, fuzzification, deduction framework and defuzzification assessed all 


\section{A PV MODULE INTEGRATED CONVERTER FOR ENHANCED PERFOMANCE IN STANDALONE AND DC MICROGRID APPLICATIONS}

through the demonstrating degree. The dc-dc converter will likewise be carried out by using the structure situations assessed within the reenactments.

\section{LITERATURE SURVEY}

As indicated by the past setting, the utilization of most extreme power point (MPPT) controllers is as of now expanding [4]. These gadgets are in charge of directing the accuse of the battery, controlling the time when the PV modules produce the best measure of vitality conceivable, paying little mind to varieties in climatic conditions. The utilization of MPPT controllers in PV frameworks have the accompanying points of interest: 1 . They yield more power, contingent upon climate also temperature; 2.They allow the association of PV modules in arrangement to build the voltage of the framework, which decreases he wiring measure and includes adaptability; 3 . They propose a price investment funds in the communication cable required for the establishment of the PV framework.

Rather than MPPT controllers, conventional controllers make an immediate association of the PV modules to the batteries, which necessitate that the modules work in a voltage go that is underneath to the voltage in most extreme power point. For instance, on account of a $12 \mathrm{~V}$ framework, the string voltage can change among $11 \mathrm{~V}$ and $15 \mathrm{~V}$, yet the voltage at the most extreme power point is a commonplace incentive among $16 \mathrm{~V}$ and $17 \mathrm{~V}$. Because of this circumstance, with the conventional controllers the vitality that the PV modules can convey isn't amplified.

Considering the abovementioned, various looks into have been completed utilizing conventional calculations for the displaying and usage of MPPT controllers [5], of which coming up next are featured: bother plus watch $(\mathrm{P} \& \mathrm{O})$ [6],[7], adjusted P\&O [8], [9], fragmentary short out current [10], partial open circuit voltage [11], sliding mode control [12], [13] and gradual conductance [14]. The P\&O calculation has been utilized generally, yet it has been demonstrated that this strategy has issues for following the MPP when there are unexpected change within sun powered irradiance [15].

Likewise, calculations dependent on man-made consciousness systems, for example, fluffy rationale [16][17] and neural systems [18] have been utilized, just as the execution of enhancement calculations, for example, glowworm swarm, insect province and honey bee settlement. These calculations are a piece of delicate processing methods and have the upside of being effectively executed utilizing implanted frameworks. Also, MPPT controllers are broadly utilized in cross breed control frameworks, in which distinctive control methods dependent on neural systems, fluffy rationale and molecule swarm enhancement have been assessed. The viability of these control methods was shown so as to accomplish a quick as well as constant reaction for genuine power control and power framework applications. The execution of latest control also advancement procedures that are for electrical power as well as vitality frameworks can be contemplated in the displaying and usage of MPPT controllers.

\section{PROPOSED WORK}

Here, within the proposed framework, the PV board is related to the DC lattice by means of an interleaved haul up converter whose responsibility proportion is gotten by the usage of PI with MPPT controller though the changing recurrence be constrained via a hysteresis-based totally irradiance flexible manipulate using SFM procedure. Use of ideal SFM within the PV framework is finished as 3 number one elements: execution of irradiance versatile SFM plan and its streamlining, desire of the appropriate MIC topology and MPPT calculation.

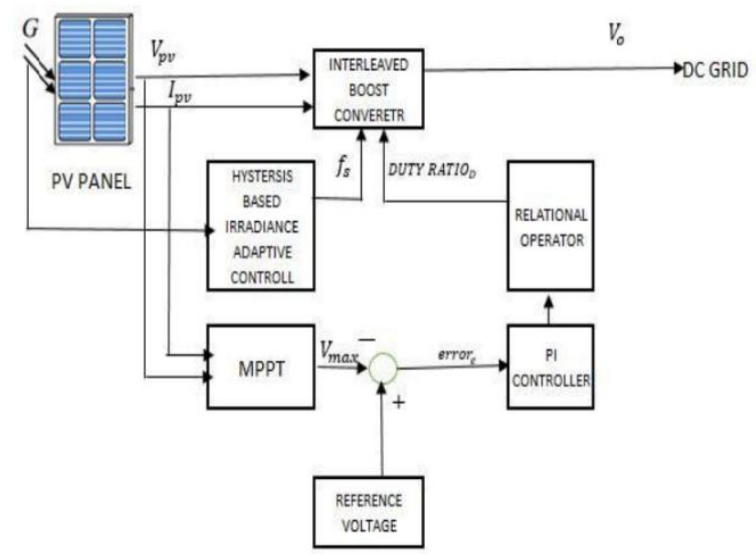

Fig 1: Block Diagram of the Proposed System

\section{Irradiance Adaptive SFM And Its Optimization}

The exceptional of PV modern-day is straight forwardly similar to the daylight based totally irradiance. next to excessive irradiance, converter can work in regular conduction mode. Henceforth, low exchanging recurrence can add to a excessive effectiveness. While at low irradiance the converter may also flow to DCM because of the low deliver present day. Right then and there the energy drawn from the information source is zero as the inductor current is 0 in DCM. Henceforth, the exchanging recurrence must be improved to maintain up the hobby of the converter in CCM. Accordingly, the exchanging recurrence $f_{s}$ is proposed to be adaptively managed with the sun based totally irradiance. The enhancement of the SFM plan require suitable desire of the accompanying parameter: the bottom exchanging recurrence $f_{\text {smin }}$, the maximum switching frequency $f_{\text {smax }}$, the frequency steps $f_{\text {smax }}, f_{s}$ Furthermore, the irradiance limits $\mathrm{G}_{\mathrm{i}}$. These parameters are chosen by means of subsequent the direction of the changing recurrence limit for the pastime of carry converter in CCM at diverse irradiance ranges. 


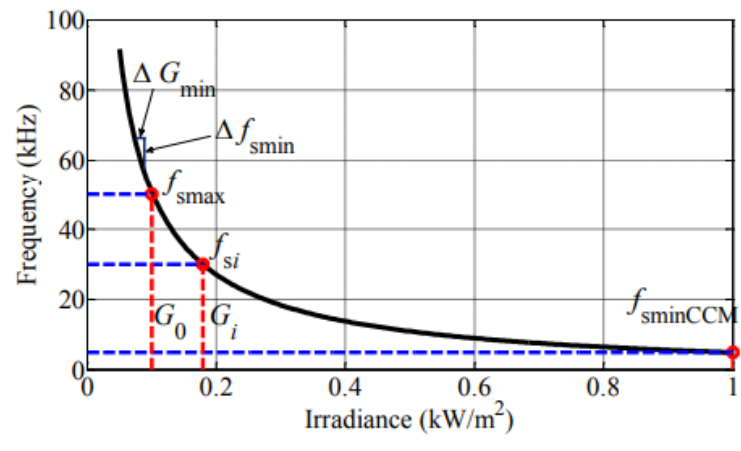

Fig 2: Trajectory of the switching frequency boundary for operating boost converter in CCM at different irradiance

At long closing, with a view to avoid an undesirable incessant range or skipping of the changing recurrence due to errors, as an example, due flying articles otherwise sensor deficiencies, hysteresis of the irradiance edges is planned. Here, the useless organizations are planned with the stop purpose that they don't surpass the CCM restriction.

\section{MIC Topology}

A 3 stage interleaved assist converter topology is projected. Fundamentally, an interleaved elevate converter is an enhancement above the common place lift converter in which numerous lift converters are related in similar. In an IBC, the level variety be dictated with the aid of the amount of elevate converters associated in parallel. These converters have a comparable exchanging recurrence and their degree flow is given by way of $360 \%$ wherein $n$ is the degree number. The upsides of utilizing IBC are minimization of swell substance in records contemporary, decrease replacing and conduction misfortunes and higher affect capacities. In this way, at excessive irradiance, the interleaved cell is actuated adaptively suitable to which the general misfortunes are diminished due to the fact the transmission misfortune lower surpasses the replacing misfortune increment. Thus, the goals of intensity change productiveness are absolutely upheld by the flexible MIC topology.

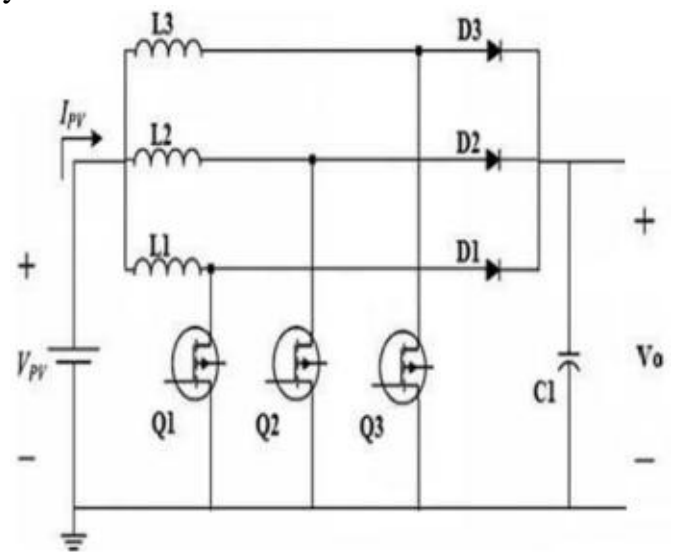

Fig 3: Three Phase interleaved boost Converter Design of proposed interleaved Boost Converter

The obligation percentage $\mathrm{D}$ for the interleaved boost converter of effectiveness $\eta$ is specified by using

$$
\text { Duty ratio, } D=1-\frac{\eta V_{\text {in }}}{V_{0}}
$$

For CCM, the selection of the inductors and capacitors for IBC is as according to the following:

$$
\begin{aligned}
L_{1,2,3} & \geq \frac{V_{\text {in } n} \cdot D \cdot T_{S}}{2 \cdot I_{\text {in }}} \\
c & \geq \frac{D \cdot V_{0} \cdot T_{S}}{R \cdot \Delta V_{0}}
\end{aligned}
$$

The equation involving the control regularity $\mathrm{f}_{\mathrm{s}}, \mathrm{PWM}$ duty percentage $\mathrm{D}, \mathrm{PV}$ unit stable state standard voltage $\mathrm{V}_{\text {in }}$ in addition to current $\mathrm{I}_{\text {in }}$ is as follow:

$$
f_{s} \geq \frac{D \cdot V_{\text {in }}}{2 \cdot I_{\text {in }} \cdot L}
$$

\section{Maximum power point tracking}

Right now, Incremental Conductance MPPT method is hired. This controller measures the steady exchange in PV array present day and voltage to are expecting the impact of a voltage exchange. Here, the incremental conductance of the PV array is utilized to calculate the signal of the trade in electricity with appreciate to voltage. The planned technique gives diverse blessings which include properly capitulate beneath quickly varying full of atmosphere circumstances, precise tracking performance, response is excessive and well organize for the extracted strength.

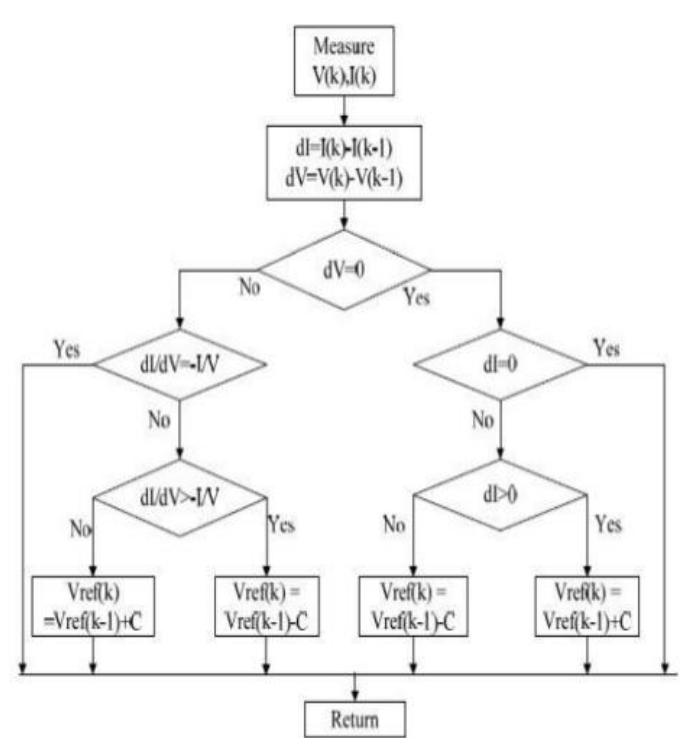

Fig 4: Flowchart of Incremental Conductance MPPT method

In this article, a PI controller is likewise planned for the interleaved enhance converter to take out the most electricity from the PV supply maintaining stable output voltage for a specific load. Subsequently, the Incremental conductance set of rules in conjunction with PI controller improve the on the whole act of the converter machine.

\section{DC micro Grid Intergration}

An adaptively managed module incorporated converter is hired for addition of PV into DC micro grid. Right now, the enter voltage of the MIC is adjusted for MPPT and the output voltage is described with the aid of the DC bus voltage manipulate devices. Right now, one hundred twenty

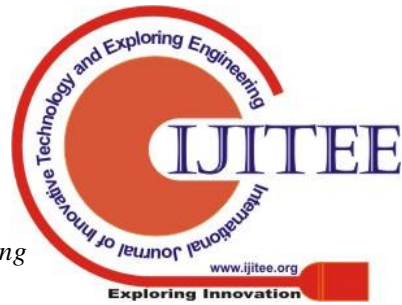




\section{A PV MODULE INTEGRATED CONVERTER FOR ENHANCED PERFOMANCE IN STANDALONE AND DC MICROGRID APPLICATIONS}

$\mathrm{V}$ is thought for DC micro grid.

\section{Fuzzy controller Design}

Fluffy control is a technique that lets in the structure of nonlinear controllers from heuristic records that comes from the expertise of an professional. Determine five show the block diagram of a fluffy controller. The fuzzification block is answerable for processing the enter signal and assigns them a fluffy cost. The set of guidelines permits a linguistic description of the variables to be managed and is primarily based on the expertise of the system. The derivation component is in charge of making an understanding of the records considering the guidelines and their club capabilities. With the defuzzification hinder, the thick records originating from the surmising system is changed into non-fluffy records that is useful for the way to be overseen.

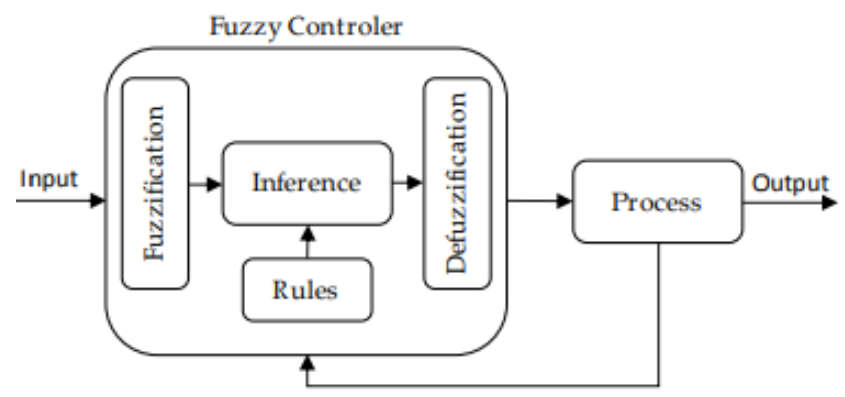

Fig 5 : Block Diagram for a Fuzzy Controller

\section{Fuzzy Controller Modelling}

The controller was displayed with the MATLAB Fluffy Logic Toolbox (MathWorks, Natick, MA, USA). A Mamdani controller with the centroid defuzzification strategy was utilized. This methodology was completed utilizing the fluffy derivation framework editorial manager (FIS supervisor) (Math Works, Natick, MA, USA). Figure 10 demonstrates the controller displayed in Simulink, for which a subsystem was performed to analyze $\Delta \mathrm{V}$ as well as $\Delta \mathrm{P}$ so as to get the Inputs of the fluffy rationale controller are the mistake of the framework which is $\mathrm{E}$ and the difference in blunder is $\Delta \mathrm{E}$ the accompanying conditions explain $\mathrm{E}$ and $\Delta \mathrm{E}$.

$$
\begin{aligned}
& \mathrm{E}(\mathrm{k})=\Delta \mathrm{P} / \Delta \mathrm{V} \\
& =\mathrm{P}(\mathrm{k})-\mathrm{P}(\mathrm{k}-1) / \mathrm{V}(\mathrm{k})-\mathrm{V}(\mathrm{k}-1)(5) \\
& \Delta \mathrm{E}(\mathrm{k})=\mathrm{E}(\mathrm{k})-\mathrm{E}(\mathrm{k}-1)
\end{aligned}
$$

where $P_{k}$ is power, $V_{k}$ is voltage of the PV board and Pk$1, \mathrm{Vk}-1$ are the past power and voltage of PV boards. To comprehend Fuzzy rationale MPPT calculation it is required to taking a gander at Figs. 7 and 8 individually. At the point when change in power $\mathrm{PP}(\mathrm{Pk}-\mathrm{Pk}-1>0)$ and voltage $(\mathrm{Vk}-$ Vk-1>0) are certain, to arrive at the MPP, the voltage ought to be expanded. That is outlined with red bolt in Fig. 5. At the point when change in power is sure and change in voltage is negative, to arrive at the MPP, the voltage ought to be diminished. That is shown with purple bolt in Fig. 7 . At the point when change in power is negative and change in voltage is certain, to arrive at the MPP, the voltage ought to be diminished. That is outlined with green bolt in Fig. 7 . At the point when change in power and voltages are is negative, to most extreme power point. Fluffy rationale control technique is connected to switch (mosfet) of lift converter to alter obligation cycle of PWM.

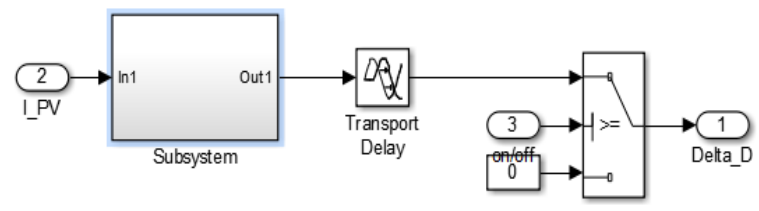

Fig 6: Fuzzy logic controller

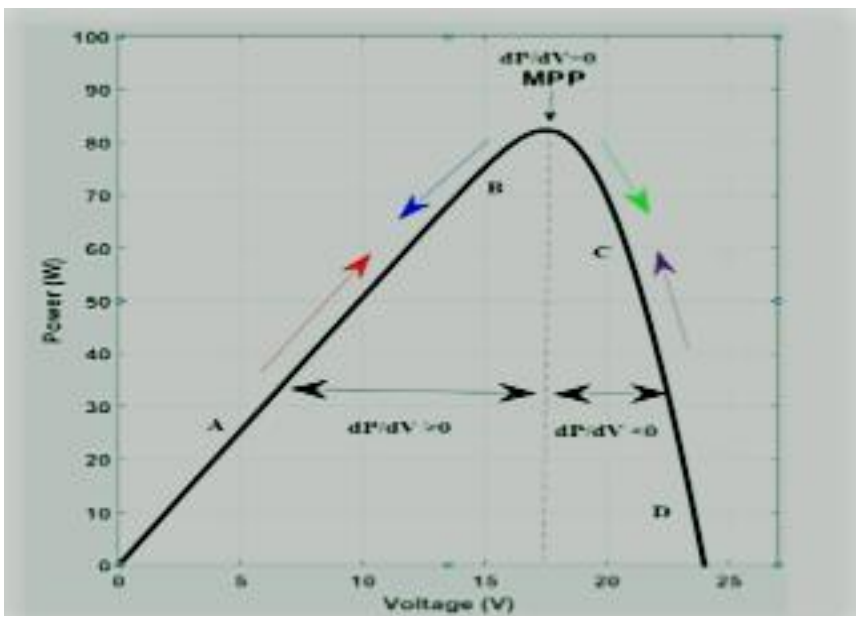

Fig 7: P-V Characteristic of PV panel for MPPT algorithm

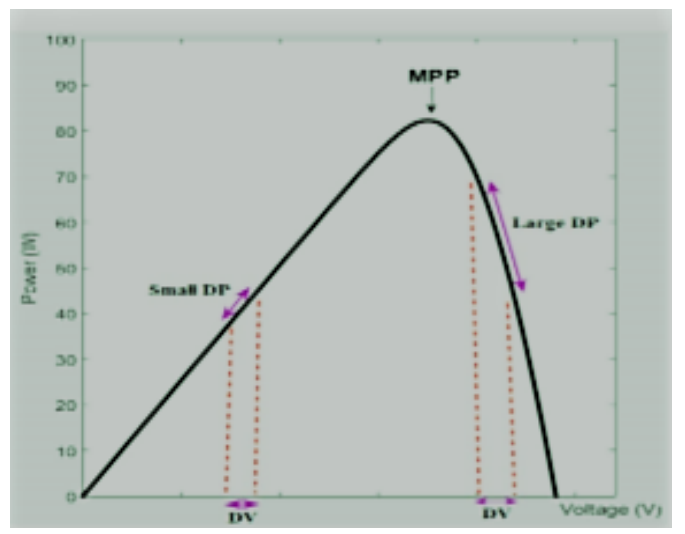

Fig 8: P-V Characteristic of PV panel for speed of MPPT

Arrive at the MPP, the voltage must be improved. That is represented with blue bolt in Fig. 7. The Fig. 8 is massive for pace of Fuzzy purpose MPPT because to take a look at right $1 / 2$ of $\mathrm{P}-\mathrm{V}$ trademark bend the distinction in strength as according to trade of voltage is little at left half of bend the condition should be managed at situation of 6 . The subsequent level is making principle table and enrollment work for Fuzzy motive. The same old table of MPPT is regarded in desk 1 , and the participation capacities are regarded in Fig.9 (a,b,c). The fluffy purpose MPPT calculation made in Matlab/Simulink is regarded in Fig. $10 \&$ Fig. 11 
Table 1:

The rule for Fuzzy logic controller (FLC)

\begin{tabular}{|l|l|l|l|l|l|l|l|}
\hline E/CE & PB & PM & PS & ZE & NS & NM & NB \\
\hline PB & ZE & ZE & ZE & NB & NB & NB & NB \\
\hline PM & ZE & ZE & ZE & NM & NM & NM & NM \\
\hline PS & ZE & ZE & ZE & NS & NS & NM & NM \\
\hline ZE & NS & NS & ZE & ZE & ZE & PS & PS \\
\hline NS & PM & PM & PS & NS & ZE & PS & ZE \\
\hline NM & PM & PM & PM & PB & ZE & ZE & NS \\
\hline NB & PB & PM & PM & PB & ZE & ZE & ZE \\
\hline
\end{tabular}
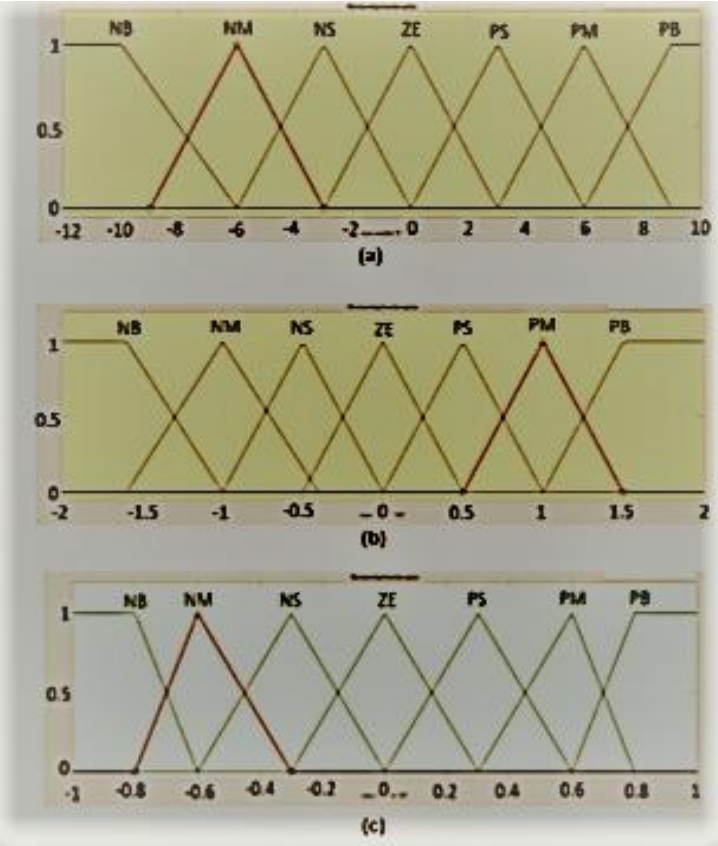

Fig 9: (a) The input of FLC (Error, E), (b) The input of FLC (Change of error $\Delta E$ ), (c) The output of FLC (Duty, D)

\section{SIMULATION RESULTS}

To check the presentation of the PV framework, diverse situations have been reenacted wherein the traditional Fuzzy motive manage MPPT is classed in exam with the fluffy controller. 4 conditions that mimic abrupt change in solar primarily based irradiance and running temperature of the PV module are displayed.

In all cases, the going with added substances had been used: $65 \mathrm{~W}$ PV module, $12 \mathrm{~V}$ battery, inductor of $416 \mu \mathrm{H}$ and capacitor of $500 \mu \mathrm{F}$; with an investigating repeat of 20 $\mathrm{KHz}$ for the dc-dc converter.

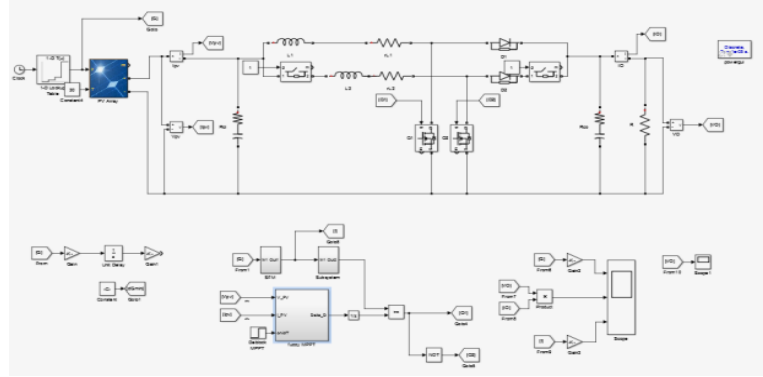

Fig 10: Irradiance step changing boost converter

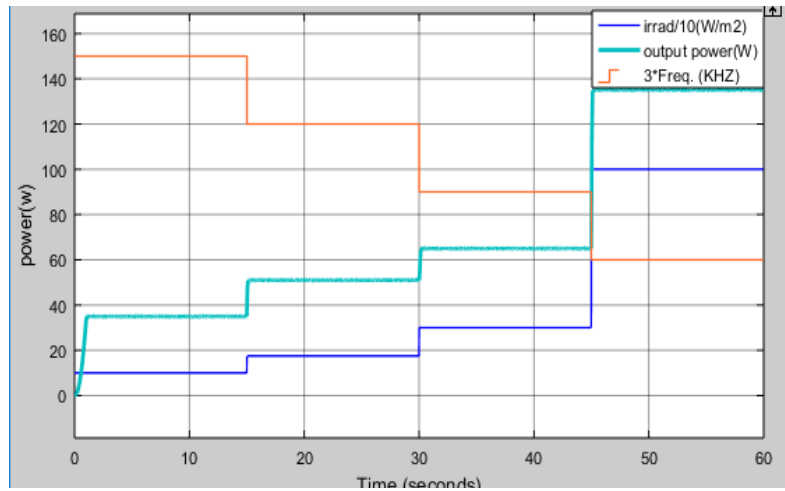

Fig 11: Standalone case simulated irradiance, switching frequency, and power: At step changing irradiance

The presentation of the PV-MIC framework for two sunlight based totally irradiance time association subsequent stepwise converting as well as consistently converting examples is talked about. To start with, the presentation beneath a stepwise converting irradiance with four ranges, $0.1 \mathrm{~kW} / \mathrm{m}^{2}, 0.35 \mathrm{~kW} / \mathrm{m} 2,0.45 \mathrm{~kW} / \mathrm{m}^{2}$, and $1 \mathrm{~kW} / \mathrm{m}^{2}$, become broke down. The daylight based totally irradiance, the exchanging recurrence, and the yield strength is delineated in Fig.11. The MIC control had the choice to differ the replacing recurrence adaptively with the sun oriented irradiance as indicated through the SFM conspire. In the imply time, the best PV electricity became powerfully observed. The converter become in CCM within the four cases. The interleaved converter cell is simply initiated at the maximum remarkable irradiance stage at a changing recurrence of $20 \mathrm{kHz}$. This thusly diminishes the yield voltage swell from $1.30 \%$ to $0.59 \%$. It is in a comparable variety concerning the other irradiance degrees.
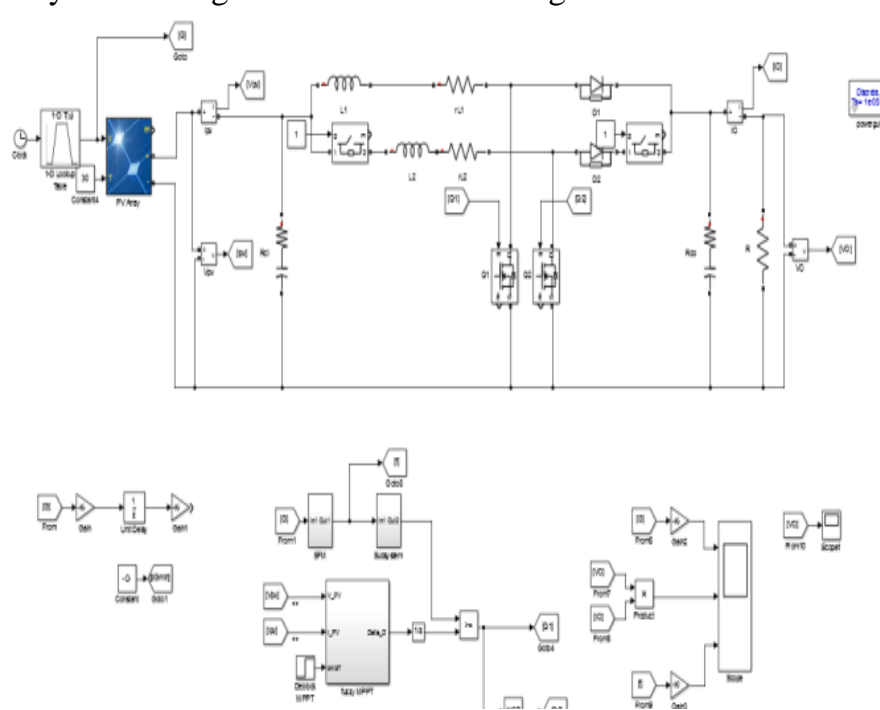

Fig 12: Irradiance continuously step changing PV boost converter 


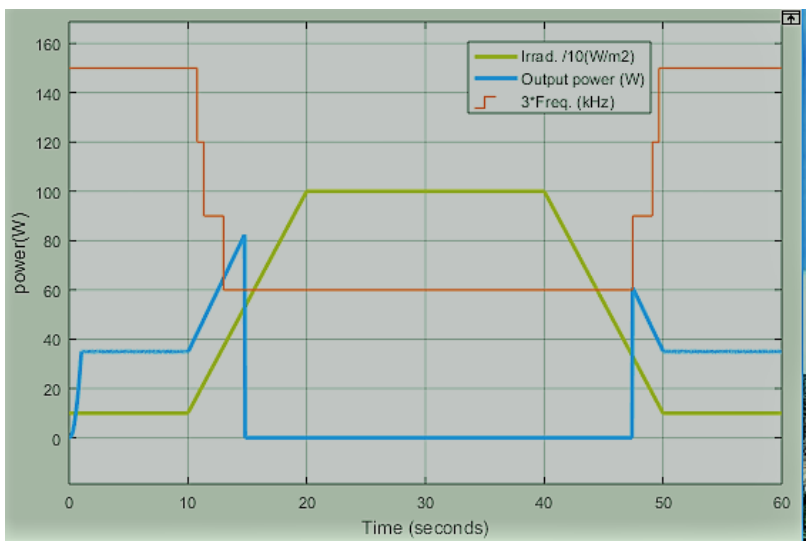

Fig 13: Standalone case simulated irradiance, switching frequency, and power: at continuously changing irradiance

The effect of frequently converting irradiance designs on both the replacing recurrence and the yield power is added in Fig. 13. On the factor when the irradiance rise and crosses $0.17 \mathrm{~kW} / \mathrm{m}^{2}$ after 10.Eight $\mathrm{s}$ into the reproduction, the exchanging recurrence is reduced from $50 \mathrm{kHz}$ to $40 \mathrm{kHz}$. Inverse manner from $40 \mathrm{kHz}$ to $50 \mathrm{kHz}$, this takes place at $0.13 \mathrm{~kW} / \mathrm{m}^{2}$ after $49.7 \mathrm{~s}$ and declining irradiance. Comparable results are watched for the advances from 40 $\mathrm{kHz}$ to $30 \mathrm{kHz}$ and from $30 \mathrm{kHz}$ to twenty $\mathrm{kHz}$. In outline, the flexible topology and control plan demonstrates the regular following of numerous irradiance designs, alteration of the replacing recurrence for retaining up activity in CCM, along with well-organized amassing of the greatest handy strength. Within the interim, the yield voltage swell was saved at the precise low ranges via utilizing each the exchanging recurrence adjustment and the interleaved cellular.

\section{CONCLUSION}

This term paper explain approximately the aim as well as achievement of a PV module coordinated converter (MIC) reasonable for boosting voltages for DC smaller scale framework programs. at this time, an irradiance tailored switching frequency is chosen with the aid of way of proposed exchanging recurrence adjustment (SFM) that is commonly excessive sufficient to keep away from activity in intermittent conduction mode. At an excessive irradiance, the SFM units a lower fee for the frequency so you can acquire high overall performance via low switching losses. This computerized method is powerful in search out the most beneficial huge range what's more, benefits of exchanging frequencies. A 3 section interleaved increase cellular is as well activated at excessive irradiance to hold a excessive stage of energy best. Hysteresis skills guide the transition among outstanding discrete switching frequencies because the irradiance adjustments. The adaptive MIC plan is complemented with the useful resource of a Fuzzy logic MPPT designed for instant monitoring. Consequently, through manner of joining the SFM with the versatile use of the improve converter interleaved cells just as a quick MPPT, goals of execution and power quality are reached

\section{REFERENCES}

1. Karami, N; Moubayed, N; Outbib, R. General review and classification of different MPPT Techniques. Renew. Sustain. Energy Rev. 2017, 68, 1-18.

2. Mohapatra, A.; Nayak, B.; Das, P.; Mohanty, K.B. A review on MPPT techniques of PV system under partial shading condition. Renew. Sustain. Energy Rev. 2017, 80, 854-867.

3. Bianconi, E.; Calvente, J.; Giral, R.; Mamarelis, E.; Petrone, G.; Ramos, C.A.; Spagnuolo, G.; Vitelli, M. Perturb and Observe MPPT algorithm with a current controller based on the sliding mode. Int. J. Electr. Power 2013, 44, 346-356.

4. Chen, M.; Ma, S.; Wu, J.; Huang, L. Analysis of MPPT Failure and Development of an Augmented Nonlinear Controller for MPPT of Photovoltaic Systems under Partial Shading Conditions. Appl. Sci. 2017, 7, 95.

5. Kwan, T.H.; Wu, X. High performance P\&O based lockon mechanism MPPT algorithm with smooth tracking. Sol. Energy 2017, 155, 816-828.

6. Alik, R.; Jusoh, A. Modified Perturb and Observe (P\&O) with checking algorithm under various solar irradiation. Sol. Energy 2017, 148, 128-139.

7. Bounechba, H.; Bouzid, A.; Snani, A.; Lashab, A. Real time simulation of MPPT algorithms for PV energy system. Int. J. Electr. Power 2016, 83, 67-78.

8. Huang, Y.P.; Hsu, S.Y. A performance evaluation model of a high concentration photovoltaic module with a fractional open circuit voltage-based maximum power point tracking algorithm. Comput. Electr. Eng. 2016, 51, 331-342.

9. Cortajarena, J.A.; Barambones, O.; Alkorta, P.; De Marcos, J. Sliding mode control of grid-tied single-phase inverter in a photovoltaic MPPT application. Sol. Energy 2017, 155, 793-804.

10. Tobón, A.; Peláez-Restrepo, J.; Villegas-Ceballos, J.P.; Serna-Garcés, S.I.; Herrera, J.; Ibeas, A. Maximum Power Point Tracking of Photovoltaic Panels by Using Improved Pattern Search Methods. Energies 2017, 10, 1316.

11. Loukriz, A.; Haddadi, M.; Messalti, S. Simulation and experimental design of a new advanced variable step size Incremental Conductance MPPT algorithm for PV systems. ISA Trans. 2016, 62, 30-38.

12. Mellit, A.; Rezzouk, H.; Messai, A.; Medjahed, B. FPGA-based real time implementation of MPPTcontroller for photovoltaic systems. Renew. Energy 2011, 36, 1652-1661

13. 13. Ramalu, T.; Mohd Radzi, M.A.; Mohd Zainuri, M.A.A.; Abdul Wahab, N.I.; Abdul Rahman, R.Z. A Photovoltaic-Based SEPIC Converter with Dual-Fuzzy Maximum Power Point Tracking for Optimal Buck and Boost Operations. Energies 2016, 9, 604

14. Hassan, S.Z.; Li, H.; Kamal, T.; Arifo glu, U.; Mumtaz, S.; Khan, L. Neuro-Fuzzy Wavelet Based Adaptive MPPT Algorithm for Photovoltaic Systems. Energies 2017, 10, 394.

15. Nabipour, M.; Razaz, M.; Seifossadat, S.; Mortazavi, S. A new MPPT scheme based on a novel fuzzy approach. Renew. Sustain. Energy Rev. 2017, 74, 1147-1169.

16. Bendib, B.; Krim, F.; Belmili, H.; Almi, M.F.; Boulouma, S. Advanced Fuzzy MPPT Controller for a Stand-alone PV System. Energy Procedia 2014, 50, 383 392. 
17. 17. Belaidi, R.; Haddouche, A.; Fathi, M.; Larafi, M.M.; Kaci, G.M. Performance of grid-connected PV system based on SAPF for power quality improvement. In Proceedings of the International Renewable and Sustainable Energy Conference (IRSEC), Marrakech, Morocco, 14-17 November 2016; pp. 1-4.

18. Chekired, F.; Larbes, C.; Rekioua, D.; Haddad, F. Implementation of a MPPT fuzzy controller for photovoltaic systems on FPGA circuit. Energy Procedia 2011, 6, 541-549 